\title{
The Research on Reliability of Typical Logistics System
}

\author{
Xueyuan Wang ${ }^{1}$, Jing Wang ${ }^{1}$ \\ ${ }^{1}$ School of Management Engineering, Zhengzhou University, Science Avenue, Zhengzhou, China \\ 947735044@qq.com
}

Keywords: Logistics system, Reliability, Series system, Parallel system

\begin{abstract}
Given the intense competition in the market, modern economic system is filled with more and more uncertainties. Logistics system is a support system of social economy, connecting social production and consumption. When a problem occurs in some parts of the logistics system, it can lead to social and economic collapse. Therefore, it is important to study the reliability of the logistics system. This paper focuses on network reliability of typical logistics system. Firstly, the logistics system is classified into two types. And a detailed description of the role of logistics unit in the two types of the logistics system is made. The computation method on reliability of the four kinds of typical logistics system is then derived based on the calculation and mathematical model of reliability of typical system. Finally,
\end{abstract} a specific case is given to illustrate the calculation of the reliability.

\section{INTRODUCTION}

The current state of economic society makes people more concerned about the reliability of service, and its reliable conditions are becoming more and more demanding. Now the economic system is becoming increasingly unreliable because of the intense market competition. And also the logistics system is the support system of social economy, connecting the production of society to the consumption of society. Thus, the network reliability of logistics system has become a concern of the society. In the logistics system, if there is a problem in the link, it can cause the collapse of whole system.

Reliability is a new engineering discipline which is used to analyze the stability of service quality. As an important part of design and operation, reliability research has been widely used in communication, water supply and power system. However, in logistics, reliability analysis is less applied.

Logistics system is a whole system composed of many logistics units, and its network reliability is of great importance to the operation of society and company. For a company in society, the network reliability of logistics system can directly affect the normal production and operation of the company. For example, to those companies that use technology such as JIT (Just In Time), the network reliability of logistics system is an important basic premise to make the production run. So it is very important to analyze the network reliability of logistics system.

\section{RESEARCH REVIEW}

The research on the network reliability of logistics system is a novel direction, many experts have pointed out the critical role of reliability analysis in some papers and periodicals. However, there have been many achievements in the application of reliability theory and other related reliability research.

Yu (2007) studied the reliability and optimization of the logistics system, connected the reliability of logistics system with its composition unit and service ability, establishing a method to measure the reliability of logistics system and analyzing how to make the logistics system cost and ability achieve the best under specific conditions. Zhou (1997) used system reliability, created a mixed block diagram for the reliability of the terminal handling system of professional bulk cargo and studied the reliability of the system by using enumeration method. Wang and Dong (2000) used Markov process to analyze the reliability of logistics system network transportation, and made a solution.

Chen A. and Yang H (1999) analyzed the factors influencing the reliability of logistics system, such as the combination of the system, the delivery time, and the ability to serve, and suggested that the redundancy of logistics service capability can directly or indirectly affect the reliability of logistics network. Since these experts focus on the reliability of military logistics, they did not value control of logistics cost, indicating that the applicable environment they have analyzed has a great limitation. Lodewijks G. (2006) improved RFID, to enhance the reliability of logistics system, and made measures to improve the accuracy of RFID. Keith J. (1995) started from the reliability of the equipment, and consider the impact that factors such as cost, operational training and monitoring have on equipment reliability.

\section{CLASSIFICATION OF LOGISTICS SYSTEM}

The logistics system is composed of the organic combination of various logistics units, and can be used to analyze the logistics unit from different perspectives, which can be classified for identifying different logistics systems.

The first type of logistics system is from the aspects of various functions of the logistics system, the various functions of the logistics system can be regarded as the logistics units of the logistics system, which suggests that the logistics unit of this kind of logistics system includes transportation, warehousing, distribution processing, loading and unloading transportation, 
distribution, logistics packaging, etc.

The second type of logistics system regards every organization shown in the practice by logistics systems as each unit of them, that is to say the logistics unit of such logistics system is: suppliers, producers, distributors, retailers, consumers, etc.

\subsection{The first type of logistics system}

In the first type of logistics system, the role of each logistics unit:

(1) Transportation. Transportation plays a key role in the process of material transfer in the whole logistics system, which connects production with consumption, achieving the purpose of production and the expectation of consumers.

(2) Warehousing. In a logistics system, warehousing is a buffer between production and consumption, which guarantees the value and value-in-use of goods.

(3) Distribution processing. The distribution processing improves the efficiency of processing, thus improving the efficiency of the whole logistics system and saving the cost of the whole logistics system.

(4) Handling. The handling links the logistics activities, making the whole logistics system run more smoothly.

(5) Distribution. Distribution improves the whole logistics system, making the whole logistics activity more rationalized. The end benefit of logistics activity is improved, thus improving the efficiency of the whole logistics system.

For each unit in the logistics system is each subsystem of logistics system such as transportation, warehousing, distribution processing, etc. But in this article, these subsystems are seen as logistics unit for the analysis reliability of the entire logistics system (Kun $\mathrm{Fu}, 2011)$.

\subsection{The second type of logistics system}

In the second type of logistics system, the role of each logistics unit:

(1) Supplier. The role of suppliers in the logistics system is to input raw materials, which is the starting point of the material flow of the whole logistics system.

(2) Producer. The producer is the starting point of the output of the logistics system, which is an indispensable link in the logistics system.

(3) Distributor. In a logistics system, distributors are an important part of the market. In the whole system, this link is not indispensable.

(4) Retail trade. The retailer is the terminal of the
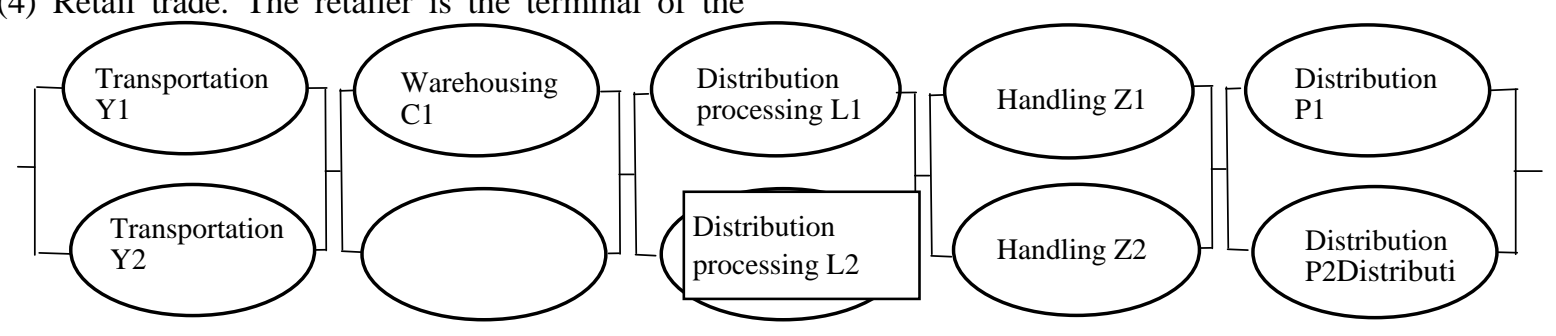

Figure 4: Typical parallel - series logistics system structure diagram. output of the logistics system, directly connecting consumers with the end of the circulation of merchandise, which is also an important link in the logistics system.

(5) Consumer. Consumers are the end point of the flow of goods in the logistics system, which is an indispensable link.

\section{ANALYSIS OF RELIABILITY OF TYPICAL LOGISTICS SYSTEM}

\subsection{Typical logistics system}

This paper introduces the classification of logistics system in section 2, this paper studies the typical logistics system of logistics unit, such as transportation, warehousing, distribution processing, handling and distribution, which is divided into typical series logistics system, typical parallel logistics system, typical seriesparallel logistics system, typical parallel- series logistics system for detailed analysis.

\subsubsection{The first type of logistics system}

Typical series logistics system structure diagram, as shown in Figure 1.

\subsubsection{Typical parallel logistics system}

Due to the fact that the logistics system cannot be completely parallel, the parallel system of one kind of logistics unit can only be analyzed. Take distribution processing as an example, as shown in Figure 2.

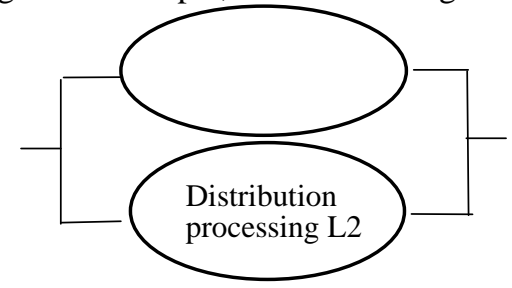

Figure 2: Typical parallel logistics system structure diagram.

\subsubsection{Typical series-parallel logistics system}

Typical serial-parallel logistics system structure diagram, as shown in Figure 3.

\subsubsection{Typical parallel - series logistics system}

Typical parallel-series logistics system structure diagram, as shown in Figure 4. 


\subsection{Mathematical reliability model of typical system}

\subsubsection{Mathematical reliability model of series system}

If the system is composed of $n$ units, and the units are independent of each other, one of the units' condition does not affect the operation of another unit. Only the $n$ units are running can the whole system run, that is to say, the system is a series system composed of $n$ units, just as what is shown in Figure 5.

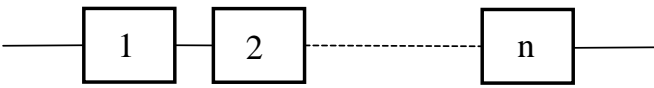

Figure 5: Structure diagram of series system.

So the reliability of the whole series system is: he whole series system is:

$$
M_{T}=\prod_{i=1}^{n} M_{i}
$$

$M_{T}$ ------ general reliability

$M_{i}$ Reliability of unit

The reliability of the series system is multiplied by the reliability of each unit, so the more units of a series system, the less reliability of the whole system.

\subsubsection{Mathematical reliability model of paralle system}

If the system is composed of $\mathrm{n}$ units, and there is only one unit running, the whole system works; The entire system fails only if all of the n units are not able to run, which means this system is a parallel system composed of $\mathrm{n}$ units, just as what has been shown in Figure 6.

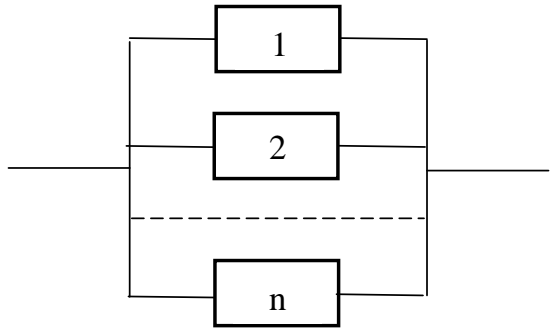

Figure 6: Structure diagram of parallel system.

(1) A system with two units in parallel

In a parallel system consisting of only two units in parallel, the probability that a unit is not working properly is: $p_{1}=1-M_{1}$; The probability that another unit is not working properly is: $p_{2}=1-M_{2}$. The probability that the two units are not working at the same time

is:

$$
p_{1} \times p_{2}=\left(1-M_{1}\right)\left(1-M_{2}\right)=1-M_{1}-M_{2}+M_{1} M_{2} \mathrm{~T}
$$$$
\text { he reliability of the whole system: }
$$$$
M_{T}=1-p_{1} \times p_{2}=M_{1}+M_{2}-M_{1} M_{2}
$$

(2) A system with $n$ units in parallel

There is $n$ units parallel to the system, the probability of the first unit of which runs improperly is: $p_{1}=1-M_{1}$; The probability that the second unit does not run properly is: $p_{2}=1-M_{2}$; The third one is: $p_{3}=1-M_{3}$ and so on. The probability that the number $n$ unit is not working properly is: $p_{n}=1-M_{n}$. The probability that the $\mathrm{n}$ units are not working at the same time is:

$$
\begin{aligned}
& p_{1} \times p_{2} \times \cdots \times p_{n}=\left(1-M_{1}\right)\left(1-M_{2}\right) \cdots\left(1-M_{n}\right) \\
& \text { The reliability of the whole system: } \\
& M_{T}=1-p_{1} \times p_{2} \times \cdots \times p_{n}=1-\prod_{i=1}^{n}\left(1-M_{i}\right)
\end{aligned}
$$

\subsubsection{Mathematical reliability model of series-parallel systems}

As shown in Figure 7, a series system is regarded as a unit, and then parallel to the two units together, which is called a series-parallel system.

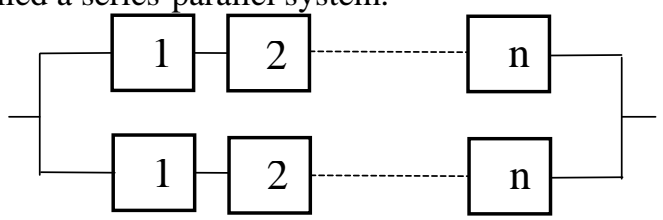

Figure 7: A structure diagram of a series-parallel system.

In a series-parallel system, the reliability of the first series system and the second series system are: $M_{T}=\prod_{i=1}^{n} M_{i}$

, The probability of non-normal operation of the first system and the second system is: $p=1-\mathrm{MT}$. The probability that the two series of series systems are not working at the same time is: $p \times p=\left(1-M_{T}\right)\left(1-M_{T}\right)$

The reliability of the whole series-parallel system: $M_{T}^{\prime}=1-p \times p=1-\left(1-\prod_{i=1}^{n} M_{i}\right)^{2}$

\subsubsection{Mathematical reliability model of parallel - series system}

As is shown in Figure 8, a parallel system consisting of two units as a unit, and then the $\mathrm{n}$ units are strung together to become a parallel-series system.

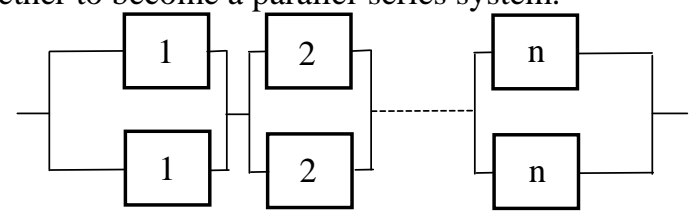

Figure 8: A structure diagram of a parallel - series system.

The reliability of the first set of parallel units is: $M_{1}^{\prime}=1-\left(1-M_{1}\right)^{2}$; The reliability of the second set of parallel units is: $M_{2}^{\prime}=1-\left(1-M_{2}\right)^{2}$; The reliability of the third set of parallel units is: $M_{3}^{\prime}=1-\left(1-M_{3}\right)^{2} ; \ldots .$. The reliability of the number n set of parallel units is $M_{n}^{\prime}=1-\left(1-M_{n}\right)^{2}$. And then this $n$ group of parallel units, overall and parallel - series system reliability is:

$$
M_{T}=M_{1}^{\prime} \times M_{2}^{\prime} \times \cdots \times M_{n}^{\prime}=\prod_{i=1}^{n}\left[1-\left(1-M_{i}\right)^{2}\right]
$$

\subsection{Calculation method of reliability of logistics unit}

Many logistics units are composed of a logistics system based on a certain link, and the reliability of the 
overall logistics system is analyzed to determine the reliability of a single logistics unit (Zhenjie Zhang,2013).

The reliability of the logistics unit refers to the probability that the service provided by the logistics unit in the specified conditions and time will remain in the specified error limit (Yunfeng Zhang,2015). The service capability curve of the logistics unit Figure 9, The standard service curve expressed by the meter curve for the hope that the logistics unit can achieve;

$\mathrm{N}$ curve denotes the error limit of a logistics service specified by the logistics unit; $\mathrm{P}$ curve represents the real logistics service curve provided by the logistics unit.

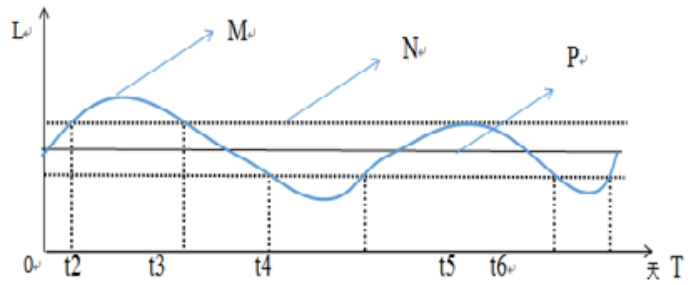

Figure 9: The service capability curve of logistics unit.

Among them, in the interval [t1, t2], [t3, t4], [t5, t6], the logistics service provided by the logistics unit exceeded the required margin of error, so it was found that the work of the logistics unit was not reliable. In the interval [t2, t3], [t4, t5], the logistics service provided by the logistics unit did not exceed the required margin of error, so it was determined that the operation of the logistics unit was reliable. Assuming the reliability of this logistics unit is $\mathrm{M}_{\mathrm{U}}$, then

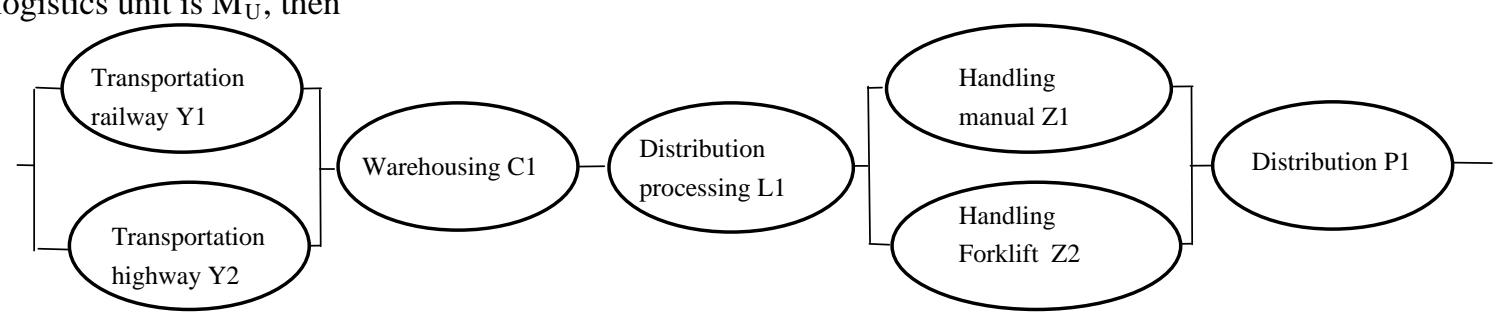

Figure 10: A company's logistics system structure diagram.

Rail transport $\mathrm{Y} 1$ and road transport $\mathrm{Y} 2$ form a parallel subsystem, the manual loading and unloading of Z1 and forklift handling Z2 also form a parallel subsystem. The two subsystems form a tandem system with warehouse $\mathrm{C} 1$, distribution processing L1 and distribution P1.

The service capability curve of the logistics system of company A in the 100 days is shown in Figure 11 to 17 , and the reliability of the logistics system of company A is analyzed.

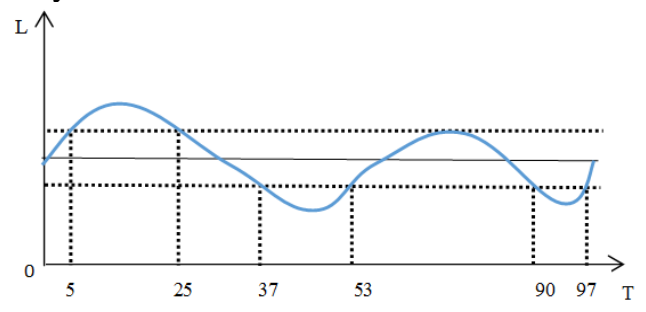

Figure 11: Railway transport Y1 service capacity curve.

$$
M_{U}=1-\frac{\sum_{k=1}^{n}\left(t_{k 2}-t_{k 1}\right)}{T}
$$

$t_{k 1}, t_{k 2}------$ The KTH observation of the logistics service provided by the logistics unit exceeds the starting and stopping time of the allowable deviation range, $(k=1,2,3, \ldots, n)$

T------ Total observation time

$n$------ The number of logistics services provided by the observed logistics unit exceeds the number of allowable deviations

\section{CASE STUDY}

\subsection{Case introduction}

The reliability of typical logistic system is analyzed by an example of company A, a domestic logistics company. A company's logistics system includes transportation, warehousing, distribution processing, loading and unloading, and distribution. Among them, there are two modes of transportation: road transportation and railway transportation. There is only one place for warehouse and circulation processing; The handling is divided into manual handling and forklift handling; There is only one way to deliver. Therefore, a company's logistics system structure diagram, is shown in Figure 10.

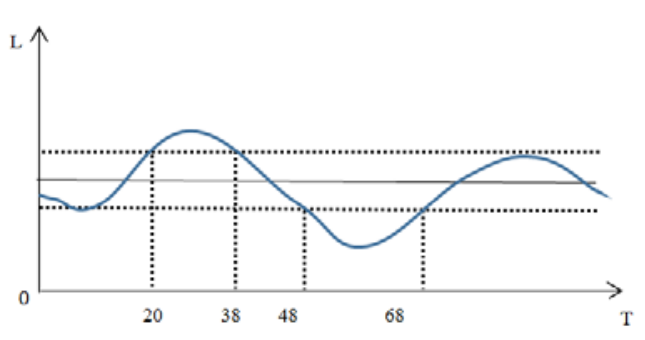

Figure 12: Road transport Y2 service capacity curve.

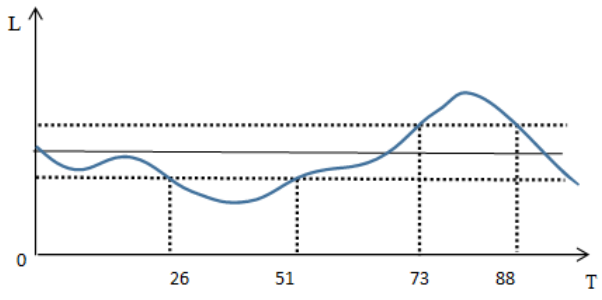

Figure 13: Warehouse C1 service capacity curve. 


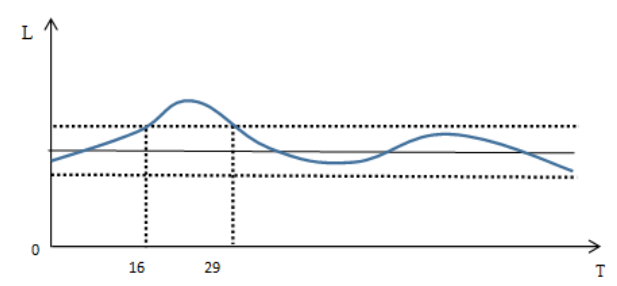

Figure 14: The service capacity curve of distribution P1.

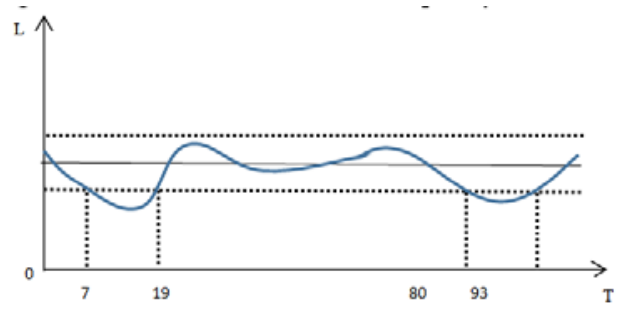

Figure 15: Manual loading and unloading of the service capacity curve of Z1.

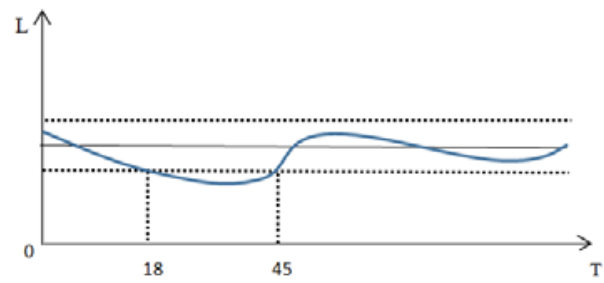

Figure 16: Forklift loading and unloading of the service capacity curve of Z2.

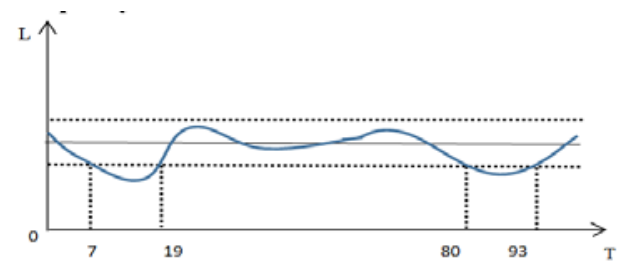

Figure 17: The service capacity curve of the distribution processing L1.

\subsection{Case study and analysis}

According to the calculation method of the reliability of the logistics unit and the service capability curve of the logistics unit of A company in 100 days, the graph can be obtained,

Reliability of the rail transport Y1:

$$
M_{Y 1}=1-\frac{(25-5)+(53-37)+(97-90)}{100}=0.57
$$

Reliability of road transport Y2:

$$
M_{Y 2}=1-\frac{(38-20)+(68-48)}{100}=0.62
$$

Reliability of warehouse C1:

$$
M_{C 1}=1-\frac{(51-26)+(88-73)}{100}=0.6
$$

Reliability of distribution processing L1:

$$
M_{L 1}=1-\frac{(19-7)+(93-80)}{100}=0.75
$$

Reliability of manual handling of Z1:

$$
M_{Z 1}=1-\frac{45-18}{100}=0.73
$$

Reliability of loading and unloading of the forklift truck Z2: $M_{Z 2}=1-\frac{29-16}{100}=0.87$

Reliability of delivery P1:

$$
M_{P 1}=1-\frac{63-48}{100}=0.85
$$

A parallel subsystem is formed by the rail transport Y1 and the road transport Y2, and the reliability of this parallel subsystem can be obtained according to the reliability calculation method of typical parallel logistics system:

$$
\begin{aligned}
& M_{Y}=M_{Y 1}+M_{Y 2}-M_{Y 1} M_{Y 2} \\
& =0.57+0.62-0.57 \times 0.62=0.8366
\end{aligned}
$$

In this paper, the reliability of the parallel subsystem can be obtained according to the reliability calculation method of the typical parallel logistics system:

$$
\begin{aligned}
& M_{Z}=M_{Z 1}+M_{Z 2}-M_{Z 1} M_{Z 2} \\
& =0.73+0.87-0.73 \times 0.87=0.9649
\end{aligned}
$$

A company's logistics system is composed of the two subsystems and warehousing processing $\mathrm{C} 1$, distribution processing L1, delivery service P1 form A cascade system, according to the typical logistics system reliability calculation method, can be concluded that the reliability of the whole logistics system:

$$
\begin{aligned}
& M_{T}=M_{Y} M_{C 1} M_{L 1} M_{Z} M_{P 1} \\
& =0.8366 \times 0.6 \times 0.75 \times 0.9649 \times 0.85=0.31
\end{aligned}
$$

The reliability of the logistics system refers to the probability that the service provided by the logistics system in the specified conditions and time will be kept in the specified error limit. The reliability of logistics system is the ability of logistics system to achieve the desired effect under certain conditions and time. So reliability is the probabilistic form of reliability, and reliability can directly reflect reliability.

Therefore, under certain conditions and within one hundred days, probability of A company's logistics system running normally to provide logistics service within a specified and allowable deviation range is 0.31 .

\section{ACKNOWLEDGEMENTS}

This research is supported by National Natural Science Foundation of China (Grant No. U1604150), Humanities \& Social Sciences Research Foundation of Ministry of Education of China (Grant No. 15YJC630148), Distinguished Young Teacher Development Foundation of Zhengzhou University (1421326092), and Key Research Foundation of University Education in Henan province (17A520058). The authors would like to thank the editors and anonymous referees for their careful and fruitful comments to improve the quality of this paper.

\section{REFERENCES}

[1] Chen A., Yang H., 1999. A capacity related reliability for transportation networks. J. Adv. Transportation.,332:183-200. [2] Lodewijks G., Veeke H.P.M., 2006. Reliability of RFID in Logistic Systems. 1-4244-0318-9/06CIEEE

[3] Keith J., 1995. The reliability of transmission and 
distribution equipment. POWER ENGINEERING JOURNAL JUNE

[4] Kun Fu., 2011. Research on business process synergy mechanism of regional logistics network. Hebei University of Technology.

[5] Kangqin Zhou., 1997. Reliability analysis of handling system of specialized bulk cargo terminal [J]. Port Engineering Technology.

[6] Xiaochuan Yu, 2007. Reliability and optimization of logistics system. Journal of Management Engineering ,01:67-
70.

[7] Youtao Wang, Ping Dong, 2000. Paper templates. Reliability analysis of a kind of logistics network model , Journal of Air Force Radar Institute,03:48-49.

[8] Yunfeng Zhang. 2015. Applying fuzzy comprehensive evaluation theory to analyze the reliability of logistics unit, logistics engineering and management, 09:99-101.

[9] Zhenjie Zhang, 2013. The reliability of the design of. multi objectives of logistics network system based on the commercial era, 16:40-41.

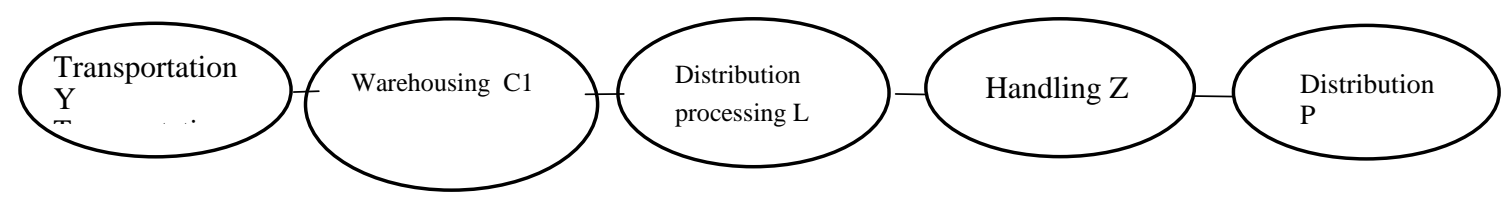

Figure 1: Typical series logistics system structure diagram.

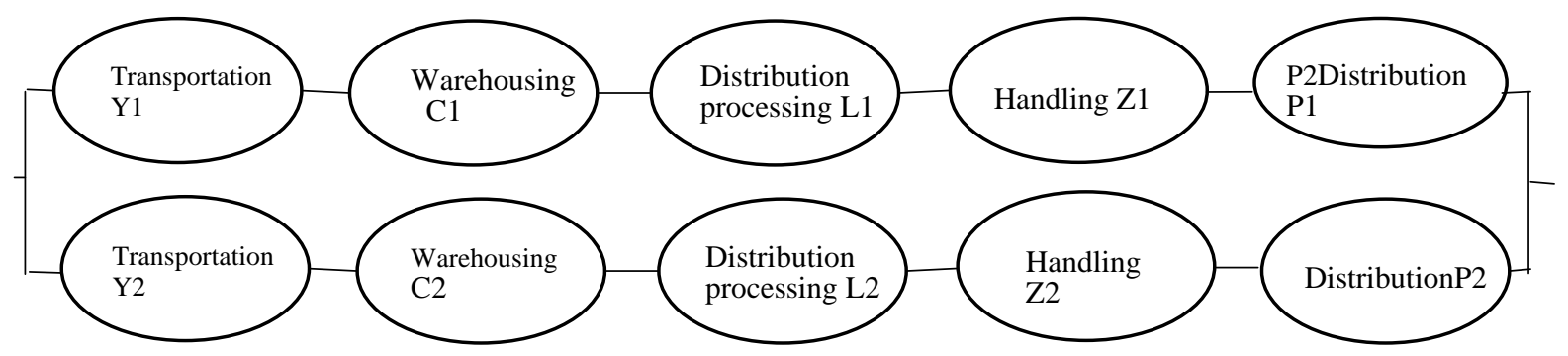

Figure 3: Typical serial - parallel logistics system structure diagram. 